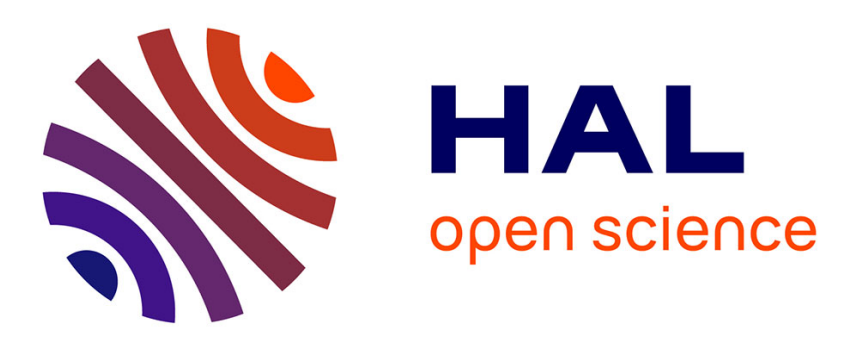

\title{
In vivo evaluation of paclitaxel-loaded lipid nanocapsules after intravenous and oral administration on resistant tumor.
}

Anne-Claire Groo, M Bossière, L Trichard, Pierre Legras, Jean-Pierre Benoît, Frédéric Lagarce

\section{To cite this version:}

Anne-Claire Groo, M Bossière, L Trichard, Pierre Legras, Jean-Pierre Benoit, et al.. In vivo evaluation of paclitaxel-loaded lipid nanocapsules after intravenous and oral administration on resistant tumor.. Nanomedicine, 2015, 10 (4), pp.589-601. 10.2217/nnm.14.124 . hal-01153494

\author{
HAL Id: hal-01153494 \\ https://hal.science/hal-01153494
}

Submitted on 4 Jun 2021

HAL is a multi-disciplinary open access archive for the deposit and dissemination of scientific research documents, whether they are published or not. The documents may come from teaching and research institutions in France or abroad, or from public or private research centers.
L'archive ouverte pluridisciplinaire HAL, est destinée au dépôt et à la diffusion de documents scientifiques de niveau recherche, publiés ou non, émanant des établissements d'enseignement et de recherche français ou étrangers, des laboratoires publics ou privés. 


\section{In vivo evaluation of paclitaxel-loaded lipid nanocapsules after intravenous and oral administration on resistant tumor}

\begin{abstract}
Aim \& methods: The aim of the present work was to encapsulate paclitaxel (Ptx) in various lipid nanocapsules (LNCS) formulations and then to compare their pharmacokinetics and efficacy on a subcutaneous isograft model in rats. Results: Three different Ptx formulations were obtained. Drug payloads ranged from 1.32 to $3.62 \mathrm{mg} P t x / \mathrm{g}$ of formulation. After oral administration the area under concentration-time curve was higher $(p<0.05)$ if Ptx was encapsulated, $(1,2$ Distearoyl-sn-glycero-3-phosphoethanolamine-N-[amino(PEG)] (DSPE-PEG-NH $\mathrm{NH}_{2}$ )) LNCs displaying the highest area under concentration-time curve $(p<0.05)$. Efficacy was better than control for standard LNCs after oral administration $(p<0.05)$ and for (DSPE-PEG-NH $\mathrm{N}_{2}$ ) LNCs after intravenous administration. Despite good absorption, (DSPE-PEG- $\mathrm{NH}_{2}$ ) LNCs failed to remain efficient after oral route. Conclusion: This study highlights the importance of efficacy studies paired to pharmacokinetic studies for nanomedicines.
\end{abstract}

Keywords: cancer $\bullet$ nanoparticles $\bullet$ oral route $\bullet$ paclitaxel $\bullet$ pharmacodynamics - pharmacokinetics • rats

Paclitaxel (Ptx) is a major anticancer drug, used mainly, in first line therapy, for the treatment of breast, ovarian, pancreas and lung cancers, which are among the most frequent tumors. Unfortunately, tumor resistance to Ptx has been observed and conduct to treatment failure [1]. In order to decrease the development to drug resistance and increase selectivity and efficacy some new formulations of Ptx and its analogs, called taxanes, have been developed [2]. In fact, the initial formulations of Ptx, Taxol ${ }^{\circledR}$ (Bristol-Myers Squibb, NY, USA) and its generics, contain Cremophor ${ }^{\circledR}$ EL, a nonionic surfactant, having many side effects such as hypersensitivity reactions, hyperlipidemia or neurotoxicity [3]. Moreover, Cremophor EL has been shown to interact with pharmacokinetics (PKs) of Ptx by reducing its clearance, increasing its area under the concentration-time curve
(AUC) but not its distribution to tissue [3]. To avoid the drawbacks of Cremophor EL (polyethoxylated castor oil), other formulation have been developed. Among them, lipid nanocapsules (LNCs), have shown promising results. LNCs can be prepared without the help of toxic organic solvent using a low-energy process that is suitable for scale-up and contain generally recognized as safe (GRAS) excipients, the formulation has been adapted to blood administration especially to avoid toxicity on blood cells [4]. LNCs are able to transport and protect drugs such as Ptx [5], etoposide [6], erlotinib [7], but also DNA [8] or siRNA [9]. Ptx-loaded LNCs (Ptx-LNCs) have shown a good toxicity profile, in fact Ptx maximum tolerated dose and LD50 were respectively multiplied by eight- and ten-fold for PtxLNCs in comparison to Taxol [10]. In the same study the structure of the LNCs were
AC Groo ${ }^{1,2}$, M Bossiere', L Trichard ${ }^{2}$, P Legras ${ }^{3}$, JP Benoit ${ }^{1,4}$ \& F Lagarce ${ }^{*, 1,4}$ 'INSERM U1066 MINT, Micro et Nanomédecines Biomimétiques, LUNAM Université, 4 Rue Larrey, 49033 Angers, CEDEX 09, France

²Ethypharm SA, Grand-Quevilly, Chemin de la Poudrière, 76120 Grand Quevilly, France

${ }^{3}$ SCAHU, LUNAM Université, Pavillon Ollivier, UFR Sciences médicales, Rue Haute de Reculée, 49045 Angers, CEDEX 01, France

${ }^{4}$ Pharmacy Department, Angers University Hospital, CHU Angers, 4 rue Larrey, 49033 Angers, CEDEX 09, France *Author for correspondence:

Tel.: +33244688568 Fax: +33 244688546

frederic.lagarce@univ-angers.fr 
observed by cryo-transmission electron microscopy (Figure 1). Ptx-LNCs improved also Ptx efficacy after intravenous injection on mice xenografted with NCIH460 cells [10]. It has also been shown that oral bioavailability of Ptx was enhanced after encapsulation in LNCs [5] and that Ptx-LNCs were stable in gastrointestinal-simulated media [11]. Moreover, these Ptx-LNCs have demonstrated their ability to crossintestinal mucus [12] and the mechanism of Ptx-LNC uptake in enterocyte has been elucidated [13]. PtxLNCs are also able to reverse multidrug resistance by interacting with $\mathrm{P}$ glycoprotein (P-gp) [14]. It has been demonstrated that P-gp which is also present on the enterocytes, was responsible for the low bioavailability of Ptx [15] and that the interaction of LNCs with P-gp on the enterocyte was complex [16].

There is now a need to optimize Ptx-LNCs formulations for bioavailability and for efficacy. Thus, the aim of the present work, was to determine the oral bioavailability of different Ptx-LNCs formulations and in the same animals to study the efficacy of those formulations, after intravenous or oral administration, against 9L rat gliosarcoma cells forming tumor that was known to be resistant to Ptx.

\section{Materials \& methods}

Materials

Captex $^{\circledR} 8000$ (tricaprylin) was obtained from Abitec Corp. (OH, USA) via Unipex (Rueil-Malmaison, France). Lipoid ${ }^{\circledR}$ S75-3 (Lip) - Soybean lecithin with $69 \%$ of phosphatidylcholine was a gift from Lipoid GmbH (Ludwigshafen, Germany). Solutol ${ }^{\circledR}$ HS15 (Sol) - mixture of free polyethylene glycol 660 $(-30 \%)$ and 12-hydroxystearate of polyethylene glycol $660(-70 \%)$, was provided by BASF (Ludwigshafen, Germany).

Amphiphilic phospholipids PEG used in the postinsertion were supplied by Avanti Polar Lipids Inc. (Alebaster, USA): 1,2 Distearoyl-sn-glycero-3-phosphoethanolamine-N-[amino (polyethylene-glycol)] with a PEG length of 2000 (DSPE-PEG-NH H $_{2}$. Chitosan was obtained from Sigma-Aldrich (MO, USA).

$\mathrm{NaCl}$ was purchased from Prolabo VWR International (Fontenay-sous-Bois, France). Ptx powder used for LNCs formulation was from Teva Pharm (OpavaKomarov, Czech Republic). Injectable solution of Ptx at $6 \mathrm{mg} / \mathrm{ml}$ (Taxol generic) was obtained from Teva Pharm (La Défense, France). Water for injectable preparation was obtained from COOPER (Melun, France). Normal saline solution was obtained from Aguettant (Saint-Fons, France). HPLC grade acetonitrile, methanol, dimethyl sulfoxide and tetrahydrofurane were from Fisher Bioblock (Illkirch, France). LC-MS grade acetonitrile, methanol and formic acid were from Fisher Bioblock.
Preparation \& characterization of blank LNCs \& Ptx-LNCs

LNCs were prepared according to the original process described by Heurtault et al. including several changes [17]. Briefly, Captex 8000 (29\%,w/w) and Lipoid $^{\circledR}$ S75-3 $(1.6 \%, w / w)$ were mixed and heated at $85^{\circ} \mathrm{C}$. Solutol ${ }^{\circledast} \mathrm{HS} 15$ (24.15\%, w/w), $\mathrm{NaCl}(1.77 \%$, $\mathrm{w} / \mathrm{w})$ and water $(43.48 \%, \mathrm{w} / \mathrm{w})$ were added and mixed under magnetic stirring. Three cycles of progressive heating and cooling between 70 and $90^{\circ} \mathrm{C}$ were then carried out and followed by an irreversible shock induced by dilution with $2^{\circ} \mathrm{C}$ purified water $(73 \%$, $\mathrm{v} / \mathrm{v})$ added to the mixture at $78^{\circ} \mathrm{C}$. Magnetic stirring (at $300 \mathrm{rpm}$ ) was then applied to the suspension of LNCs for $5 \mathrm{~min}$ at room temperature. To prepare PtxLNCs, $29.3 \mathrm{mg}$ of Ptx was dissolved in Captex 8000 in the presence of ethanol $(800 \mathrm{mg})$ and the solvent was evaporated at $85^{\circ} \mathrm{C}$ before use. LNCs were then prepared as previously described.

\section{Preparation of postinserted LNCs \& LNCs with chitosan}

Blank LNC suspensions and Ptx-LNCs were incubated for $60 \mathrm{~min}$ at $45^{\circ} \mathrm{C}$ with $20 \mathrm{mg} / \mathrm{ml} \mathrm{DSPE}-P_{20 G_{200}}$ amino. Reaction was stopped by freezing during $1 \mathrm{~min}$. Chitosan was incubated at $25^{\circ} \mathrm{C}$ during $30 \mathrm{~min}$ with Ptx-LNCs to obtain a final concentration of $5 \mathrm{mg}$ chitosan $/ \mathrm{ml}$ and with a small quantity of $\mathrm{NaOH} 0.1 \mathrm{~N}$.

\section{Characterization of blank LNCs \& Ptx-LNCs}

The size of the nanoparticles was measured by dynamic light scattering (DLS) on a ZetasizerNano series DTS 1060 (Malvern Instruments SA, Worcestershire, UK). To determine Ptx-encapsulation ratio, LNCs were filtered using a Minisart ${ }^{\circledR} 0.2 \mu \mathrm{m}$ filter (Vivascience AG, Hanovre, Germany) after formulation in order to eliminate Ptx crystals that were not encapsulated. Three samples of filtrate were prepared by dissolution of an exact quantity of LNC suspension in a $96 / 4(\mathrm{v} / \mathrm{v})$ methanol/tetrahydrofurane solution and then filtrated on a Minisart ${ }^{\circledR} 0.2 \mu \mathrm{m}$ filter in order to eliminate the residual components of the LNCs. A $15 \mu \mathrm{l}$ aliquot of each filtrate was injected in triplicate into the HPLC column. Chromatography was performed using a Waters ${ }^{\circledR} 717$ plus autosampler, Waters 600 controller and Waters 2487 Dual Absorbance Spectrometer (Waters SA, Saint-Quentin-enYvelynes, France) with an XTerra ${ }^{\circledR}$ C18-ODB 150 $\mathrm{mm} \times 4.60 \mathrm{~mm}$ column (Waters, Milford, Ireland) and an UV detector set at $227 \mathrm{~nm}$. The flow rate was set to $1 \mathrm{ml} / \mathrm{min}$. The gradient was obtained by mixing proportion of phase A (water) and phase B (acetonitrile). Initially, the mobile-phase composition was $50 \% \mathrm{~B}$; a linear gradient was applied to reach 
a composition of $85 \% \mathrm{~B}$ after $7 \mathrm{~min}$, maintained for $2 \mathrm{~min}$ and then returned to the initial conditions. Quantification was achieved by comparing observed peak area ratios of Ptx in the samples to a calibration curve obtained under the same experimental conditions. The detection limit was $10.0 \mathrm{mg} / \mathrm{l}$ and the quantification limit was $20.0 \mathrm{mg} / \mathrm{l}$. The mean drug payload (mg of Ptx/g of LNCs dispersion) of each batch of LNCs dispersion and the standard deviation were calculated from three samples. The encapsulation efficiency (\%) was determined by dividing the measured drug payload by the theoretical drug payload.

\section{In vivo studies}

Animals

Syngeneic Fischer F344 female rats weighing 160-175 g were obtained from Charles River Laboratories France (L'Arbresle, France). All experiments were started on 9-week-old female Fisher rats. The animals were anesthetized with an isofluorane/oxygen gas mixture for ectopic models (subcutaneous isograft). Animal care was carried out in strict accordance to French Ministry of Agriculture regulations. Animals in this study were handled in accordance with the Principles of Laboratory Animal Care [56]. This experiment was also carried out in accordance with the 'Good practice guide to the administration of substances and removal of blood, including routes and volumes' adopted by the European Federation of Pharmaceutical Industries Associations (EFPIA) and the European Centre for the Validation of Alternative Methods (ECVAM) in 2001. The study was accepted by our regional ethical committee (CEEA) under $\mathrm{N}^{\circ} \mathrm{CEEA}$ 2012.70.

\section{Tumor model}

Tumor cell line

Rat 9L gliosarcoma cells were obtained from the European Collection of Cell Culture (Salisbury, UK; catalogue number: 94110705). The cells were grown at $37^{\circ} \mathrm{C}$ and $5 \% \mathrm{CO}_{2}$ in Dulbecco-modified eagle medium (DMEM) with glucose and l-glutamine (BioWhittaker, Verviers, Belgium) containing 10\% fetal calf serum (FCS; BioWhittaker) and 1\% antibiotic and antimycotic solution (Sigma-Aldrich, MO, USA).

\section{Ectopic isograft model}

A cultured tumor monolayer was trypsinized, washed twice with Eagle's minimal essential medium (EMEM) without FCS or antibiotics, counted, and resuspended to the final desired concentration. Finally, animals received subcutaneous injections of $1.5 \times 10^{6} 9 \mathrm{~L}$ cells into the right thigh.

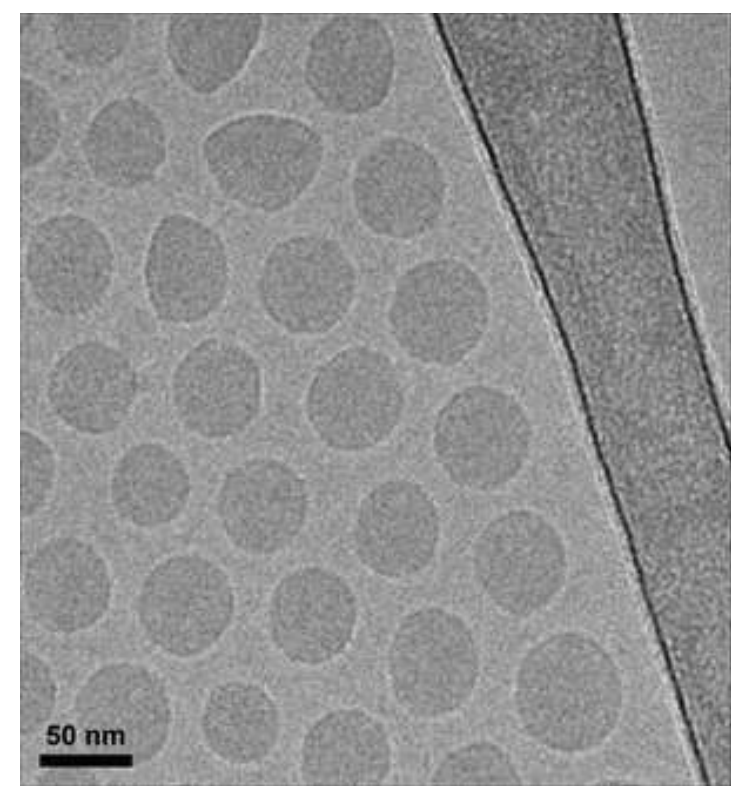

Figure 1. Cryo-TEM image of lipid nanocapsules. Reproduced with permission from [10].

\section{Treatment methodology}

Experiments were conducted in a parallel study design with the following treatment groups: treatment 1 , oral dose of normal saline solution; treatment 2 , oral dose of blank LNCs; treatment 3, oral dose of $25.0 \mathrm{mg} / \mathrm{kg}$ Ptx with Ptx commercial formulation diluted with water $(3.8 \mathrm{mg} \mathrm{Ptx} / \mathrm{g})$; treatment 4 , intravenous dose of $5.0 \mathrm{mg} / \mathrm{kg}$ Ptx with Ptx commercial formulation diluted with normal saline (1.9 mg Ptx/g); treatment 5, oral dose of $25.0 \mathrm{mg} / \mathrm{kg}$ Ptx with LNC dispersion; treatment 6 , intravenous dose of $5 \mathrm{mg} / \mathrm{kg}$ Ptx with LNC dispersion (1.9 mg Ptx/g); treatment 7, oral dose of $25.0 \mathrm{mg} / \mathrm{kg}$ Ptx with $\mathrm{PEG}_{2000}$-amino postinserted LNC dispersion; treatment 8 , intravenous dose of $5 \mathrm{mg} / \mathrm{kg}$ Ptx with $\mathrm{PEG}_{2000}$-amino postinserted LNC dispersion (1.9 mg Ptx/g); treatment 9, oral dose of $25.0 \mathrm{mg} / \mathrm{kg}$ Ptx with LNC-chitosan dispersion; treatment 10 , oral dose of blank $\mathrm{PEG}_{2000}$-amino postinserted LNC dispersion (Table 1).

For oral administration (treatments 1, 2, 3, 5, 7, 9 and 10), preparations were administered by gastric intubation after weighing in a syringe to achieve a target dose of Ptx of $25 \mathrm{mg} / \mathrm{kg}$, in other words, a dosing volume of approximately 1.0-2.0 ml. For intravenous bolus experiments, Ptx was administered into the lateral tail vein with an approximate volume of $0.5 \mathrm{ml}$ of preparation to achieve a target dose of Ptx of $5.0 \mathrm{mg} / \mathrm{kg}$ (treatment 4, 6, 8).

Each group was composed of seven rats. Each animal underwent three treatments (one treatment per week) during 3 weeks. On day 7 after cell injection, treatment protocol started. 
PK study

Efficacy study and PK study were performed on the same animals. Experiments were performed after the first treatment on day 7 after injection on female Fischer F344 rats that were given no food overnight, but with access to water. Plasma concentrations of control groups (1, 2 and 10) were not studied.

Blood samples were collected over $12.0 \mathrm{~h}$ (intravenous) or $10.0 \mathrm{~h}$ (per os) via intracardiac punction into heparinized tubes at predose, then after 20, 60, 90, $120,240,420$ and $600 \mathrm{~min}$ for oral groups, and at predose, then after 5, 20, 60, 90, 120, 240 and $720 \mathrm{~min}$ for intravenous groups. Blood samples were centrifuged for $10 \mathrm{~min}$ at $2000 \mathrm{~g}$. The supernatant plasma fraction was transferred to a clean vial and stored at $-20^{\circ} \mathrm{C}$ for analysis.

\section{In vivo antitumor activity}

Rats were observed every 2 days, and body weight measurements and signs of stress (e.g., lethargy, ruffled coat and ataxia) were used to detect toxicities. Animals with ulcerated tumors or whose tumors weight exceeded $20 \%$ of body weight were euthanized for ethical considerations. The length and width of each tumor were regularly measured using a digital caliper, and tumor volume was estimated with the mathematical ellipsoid formula given in the followed equation:

- Volume $\left(\mathrm{mm}^{3}\right)=(\pi / 6) \times$ width $^{2}(\mathrm{~mm}) \times$ length $(\mathrm{mm})$

Quantification of Ptx in plasma samples

An aliquot $(50 \mu \mathrm{l})$ of plasma sample was mixed with $30 \mu \mathrm{l}$ of methanol, $20 \mu \mathrm{l}$ of internal standard solution (docetaxel; $120 \mathrm{ng} / \mathrm{ml}$ in methanol) and $100 \mu \mathrm{l}$ of $\mathrm{H}_{3} \mathrm{PO}_{4}$ solution at $4 \%$. After mixing, the mixture was centrifuged for $5 \mathrm{~min}$ at $10,000 \mathrm{rpm}$ at $4^{\circ} \mathrm{C}$. After the solution was purified using Oasis ${ }^{\circledR}$ micro elution Plate (Waters), then Ptx and docetaxel were eluted by $200 \mu \mathrm{l}$ of methanol with $0.1 \%$ of formic acid.

Chromatography was performed using a Waters Alliance $^{\circledR} 2695$ system (Waters SA) with an Uptisphere ${ }^{\circledR}$ C18-ODB $150 \times 2.0 \mathrm{~mm}, 5 \mu \mathrm{m}$ column (Interchrom, Montluçon, France). The mobile phase consisted of phase $\mathrm{A}(0.1 \%$ formic acid in water) and phase $\mathrm{B}(0.1 \%$ formic acid in methanol). In initial conditions, the mobile-phase composition was $30 \% \mathrm{~B}$; a linear gradient was applied to reach a composition of $98 \%$ B after $5 \mathrm{~min}$, maintained for $0.5 \mathrm{~min}$ and then set to return to initial conditions. The flow rate was $0.3 \mathrm{ml} / \mathrm{min}$. The total HPLC effluent was directed into a Quattro Micro ${ }^{\circledR}$ triple quadruple mass spectrometer (Waters SA). Ionization was achieved using turbo ion spray in positive ion mode. The mass spectrometer operated in multiple reaction monitoring $(\mathrm{MRM})$ mode. The $(\mathrm{M}-\mathrm{H})^{+} \mathrm{m} / \mathrm{z}$ transitions for each compound were $854.1 \rightarrow 286.1$ for Ptx and $808.2 \rightarrow 226.1$ for docetaxel (internal standard). A typical retention time of Ptx and docetaxel was found to be 6.44 and 6.54 min, respectively. Quantification was achieved with QuantLynx ${ }^{\circledR}$ (Waters SA) by comparison of the observed peak area ratios of Ptx and internal standard of the samples to a calibration curve obtained under the same conditions. The range of linear response was 1 to $19,000 \mathrm{ng} / \mathrm{ml}$. The lower limit of detection was $0.3 \mathrm{ng} / \mathrm{ml}$ and the lower limit of quantification was $1 \mathrm{ng} / \mathrm{ml}$.

\section{PK data analysis}

The concentration-time data were analyzed by Kinetica (v6; Innaphase, PA, USA) using noncompartmental analysis to obtain the PK parameters of Ptx.

The maximal concentration $\left(\mathrm{C}_{\max }\right)$ corresponded to the highest observed concentration and was not extrapolated from the plasma profile.

The area under the plasma Ptx concentration-time curve $\left(\mathrm{AUC}_{\text {last }}\right)$ was calculated using the linear trapezoidal method between the experimental time points from initial sampling to $600 \mathrm{~min}$ (oral route) or $720 \mathrm{~min}$ (intravenous route). The mean residence time $\left(\mathrm{MRT}_{\text {last }}\right)$ was calculated using the intravenous dataset:

$$
\text { - } \mathrm{MRT}_{0-\mathrm{t}}=\mathrm{AUMC}_{0-\mathrm{t}} / \mathrm{AUC}_{0-\mathrm{t}} \text {. }
$$

\section{Statistical analysis}

For statistical analysis the Mann-Whitney U nonparametric test was used. The data were computed using Prism ${ }^{\circledR} 5$ software (GraphPad Software, Inc., CA, USA). The statistical significance was assessed for a p-value under 0.05 .

\section{Results}

Characterization of blank LNCs, postinserted blank LNCs and Ptx-LNCs.

Blank LNCs and Ptx-LNCs have been successfully prepared with or without including a step of DSPE$\mathrm{PEG}_{2000}-\mathrm{NH}_{2}$ postinsertion or chitosan adsorption. Ptx has been encapsulated in all the formulations. The characteristics of the obtained nanoparticles are described in Table 1.

\section{PKs of Ptx \& Ptx-LNCs}

Plasma concentration versus time profiles of Ptx after oral administration of Ptx commercial formulation, or Ptx-LNCs that have been modified with postinsertion of $\mathrm{PEG}_{2000}$-amino or with chitosan are presented in Figure 2. The plasma concentration versus time profiles of Ptx after intravenous injection are presented in Figure 3, for the following formulations: Ptx commercial formulation, $\mathrm{PEG}_{2000}$-amino postinserted LNCs and standard LNCs (not postinserted). 
Table 1. Properties of lipid nanocapsules and paclitaxel commercial formulations.

\begin{tabular}{|c|c|c|c|c|c|}
\hline Formulation & $\begin{array}{l}\text { Size, Z-average } \\
(\mathrm{nm})\end{array}$ & PDI & $\begin{array}{l}\text { Zeta potential } \\
(\mathrm{mV})\end{array}$ & $\begin{array}{l}\text { Drug payload } \\
(\mathrm{mg} \operatorname{Ptx} / \mathrm{g})\end{array}$ & $\begin{array}{l}\text { The encapsulation } \\
\text { efficiency }(\%)\end{array}$ \\
\hline Standard LNCs iv. & $52.7 \pm 0.9$ & $0.035 \pm 0.010$ & $-7.2 \pm 1.2$ & $1.79 \pm 0.10$ & 94 \\
\hline $\begin{array}{l}\text { LNCs postinserted with } \mathrm{PEG}_{2000^{-}} \\
\text {amino iv. }\end{array}$ & $57.8 \pm 1.2$ & $0.042 \pm 0.007$ & $2.6 \pm 1.1$ & $1.32 \pm 0.17$ & 70 \\
\hline LNCs with chitosan p.o. & $66.7 \pm 3.6$ & $0.171 \pm 0.008$ & $13.8 \pm 1.6$ & $3.62 \pm 0.13$ & 95 \\
\hline Blank LNCs p.o. & $55.6 \pm 2.3$ & $0.036 \pm 0.008$ & $-5.3 \pm 1.3$ & - & - \\
\hline $\begin{array}{l}\text { Blank LNCs postinserted with } \\
\text { PEG }_{2000} \text {-amino p.o. }\end{array}$ & $67.3 \pm 1.6$ & $0.082 \pm 0.013$ & $3.1 \pm 0.7$ & - & - \\
\hline
\end{tabular}

iv.: Intravenous; LNC: Lipid nanocapsule; p.o.: Per os; Ptx: Paclitaxel.

PK parameters $\left(\mathrm{C}_{\max }, \mathrm{AUC}_{\text {last }}\right.$ and $\left.\mathrm{MRT}_{\text {last }}\right)$ are given in Table 2. When Ptx was loaded in standard LNCs and administered intravenously, the $\mathrm{C}_{\text {max }}$ was decreased from $16759 \pm 2336$ (Ptx alone) to $9905 \pm 1517 \mathrm{ng} / \mathrm{ml}$ and the $\mathrm{AUC}_{\text {last }}$ was significantly decreased from $5 \cdot 2 \cdot 10^{5} \pm 1.3 .10^{5}$ to $2.5 .10^{5} \pm 2.9 \cdot 10^{4} \mathrm{ng} \cdot \mathrm{h} / \mathrm{ml}(\mathrm{p}<0.05)$. Whereas, when Ptx was loaded in PEG $_{2000}$-amino postinserted LNCs intravenously administered, its profile was not significantly different from that of Ptx commercial formulation. After oral administration, the $\mathrm{AUC}_{\text {last }}$ of Ptx and $\mathrm{C}_{\max }$ were significantly higher if the drug was encapsulated in LNCs in comparison to the Ptx commercial formulation $(\mathrm{p}<0.05)$. After oral administration, the $\mathrm{AUC}_{\text {last }}$ of Ptx and $\mathrm{C}_{\max }$ were significantly higher for $\mathrm{PEG}_{2000}$-amino postinserted LNCs in comparison to standard LNCs $(\mathrm{p}<0.05)$.

\section{Pharmacodynamics of Ptx formulations}

Tumoral volume versus time profiles and tumoral volume at Day 25 postimplantation after oral and intravenous administration are presented in Figure 4. The tumoral volumes have been found smaller after oral administration of standard LNCs and after intravenous injection of $\mathrm{PEG}_{2000}$-amino postinserted LNCs in comparison with control group (i.e., treated with physiologic serum; $\mathrm{p}<0.05$ ).

\section{Discussion}

Ptx was incorporated in standard LNCs with a high encapsulation efficiency ( $>94 \%)$. No loss of encapsulated Ptx was observed after chitosan adsorption. However, a slight loss of encapsulated Ptx was observed after the modification process by postinsertion (the encapsulation efficiency was slightly over $70 \%$ ). No effect of the loading of Ptx on the size and the zeta potential of LNCs was observed. Ptx incorporation did not change the size distribution. The oral doses were higher than intravenous doses to take the low bioavalability of oral Ptx into account. The oral formulations were more concentrated than the intravenous formulations, in order to limit the oral administered volumes. Zeta potential was almost zero for postinserted LNCs and standard LNCs. It was positive for LNCs with chitosan. The modification processes were efficient because they changed the standard LNC properties: a size increase for postinserted LNCs, and a size increase and a zeta potential change for LNCs with chitosan.

In order to determine the oral bioavailability of different Ptx-LNCs formulations and to find a relation between AUC and pharmacological effect after intravenous or oral administration, PK and pharmacodynamic (PD) studies were performed on the same animal model.

The range of Ptx oral doses administered in rats found in the literature is large. Doses ranging from 0.5 to $10 \mathrm{mg} / \mathrm{kg}$ were used for intravenous route [18-22] and ranging from 2 to $100 \mathrm{mg} / \mathrm{kg}$ for oral route [18,23-25] but oral doses were not below $10 \mathrm{mg} / \mathrm{kg}$ in most studies [26-31]. The calculated $(\mathrm{mg} / \mathrm{kg})$ dose by extrapolation for rat is around sixfold higher than for adult human because the surface area to weight ratio depends on species [32]. For example, a $175 \mathrm{mg} / \mathrm{m}^{2}$ dose classically used for intravenous treatment in clinic corresponds to a dose of $29 \mathrm{mg} / \mathrm{kg}$ for rats. In order to avoid toxicity, the lower dose of $5 \mathrm{mg} / \mathrm{kg}$ was chosen for intravenous route. Taxol and its generics contain Cremophor EL which decreases oral absorption of Ptx [33]. Moreover, this compound influences the PKs of Ptx [34]. Cre- 


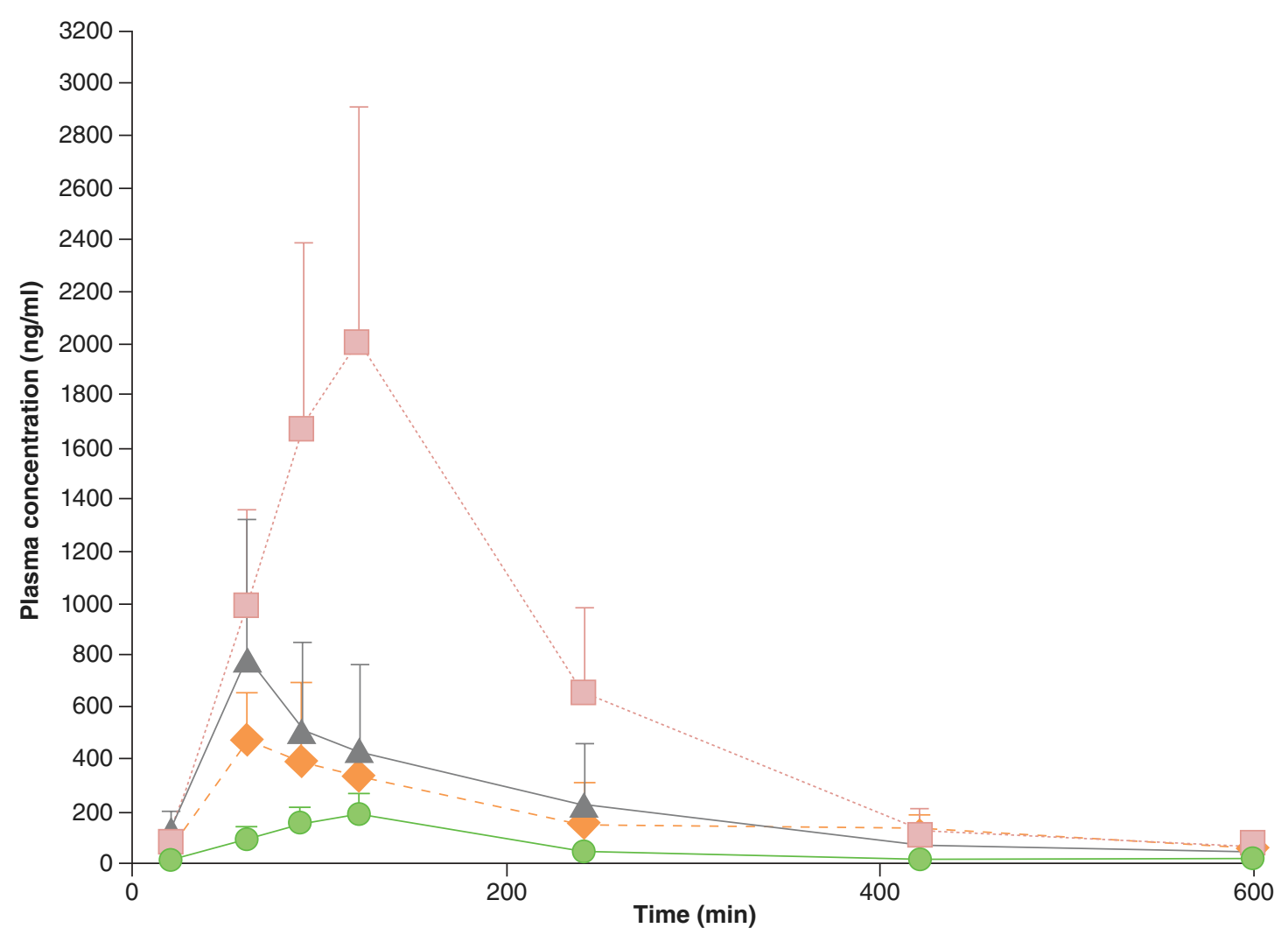

Figure 2. Plasma paclitaxel concentration-time profiles after the oral administration of a $25 \mathrm{mg} / \mathrm{kg}$ dose of paclitaxel. Orange diamonds: standard lipid nanocapsules (LNCs; $n=6)$; pink squares: LNCs postinserted with $\operatorname{PEG}_{2000}$-amino $(n=7)$; gray triangles: LNCs with chitosan $(n=7)$; green circles: Ptx commercial formulation $(n=7)$. Each point represents mean \pm standard deviation.

For color figures, please see online at: www.futuremedicine.com/doi/full/10.2217/NNM.14.124

mophor EL causes an apparent nonlinear disposition profile of Ptx after intravenous injection, by increasing its affinity in plasma and decreasing its distribution in tissues [35]. This results in nonlinear PKs. As a consequence, because intravenous Ptx commercial formulation is used as a reference, this process hampers the ability to precisely calculate absolute oral bioavailability. A previous study has showed that the bioavailability of Ptx-LNCs was around $18 \%$. This is the reason why, for the present study, it was decided that an oral dose five-times higher $(25 \mathrm{mg} / \mathrm{kg})$ than the intravenous one $(5 \mathrm{mg} / \mathrm{kg})$ should be used. Nevertheless, it can be observed that AUCs after oral treatment are not in the same order of magnitude for all formulations especially following Ptx commercial formulation, demonstrating that this a priori dose adjustment was not totally appropriate. Even if an absolute bioavailability is difficult to calculate for the reason explained above, it is possible to determine the relative bioavailability of the different formulations. As a consequence, our study shows that the relative bioavailability is enhanced by a factor of 4 and 11.2 if Ptx is encapsulated in LNCs in comparison to its formulation with Cremophor EL. Because other studies did not use the same Ptx doses, it is difficult to compare our results to others. In fact, bioavailability of Taxol varied from 18 to $0.8 \%$ with dose from 2.5 to $10 \mathrm{mg} / \mathrm{kg}$ in male Sprague-Dawley rats due to non linear PKs [23].

The AUC of Ptx commercial formulation administered intravenously was $5.2 .10^{5} \mathrm{ng} . \mathrm{min} / \mathrm{ml}$. These values were consistent with values reported in the literature of $10,584 \mathrm{ng} \cdot \mathrm{h} / \mathrm{ml}\left(=6 \cdot 3 \cdot 10^{5} \mathrm{ng} \cdot \mathrm{min} / \mathrm{ml}\right)$ of Ptx administered at the same dose of $5 \mathrm{mg} / \mathrm{kg}$ in Sprague-Dawley rats [23]. The rat origin can explain the difference observed between studies for MRT and $\mathrm{C}_{\max }$, which depends on absorption, distribution and elimination of Ptx. The effect of plasma protein on LNCs has been previously evaluated [36], in fact PEG chains at the surface of LNCs have been showed to provide stealth properties to these nanocapsules [37,38] and prolonged circulation time [39].

The oral Ptx commercial formulation produced a low mean $\mathrm{C}_{\max }(190 \pm 93 \mathrm{ng} / \mathrm{ml})$ and a low AUC $\left(3.2 \cdot 10^{4} \pm 1.6 \cdot 10^{4} \mathrm{ng} \cdot \mathrm{min} / \mathrm{ml}\right)$. This is in accordance 
with the results of another study using the same oral dose of Taxol in male Sprague-Dawley rats, where $\mathrm{C}_{\max }$ was $110 \pm 18 \mathrm{ng} / \mathrm{ml}$ and AUC $553 \pm 211 \mathrm{ng} . \mathrm{h} / \mathrm{ml}$ $\left(3.3 .10^{4} \pm 1.2 .10^{4}\right.$ ng.min $\left./ \mathrm{ml}\right)$ [31]. However, different results were obtained in a study comparing the oral absorption of Ptx solution and Ptx-loaded solid lipid nanoparticles (SLN). In this study using the same dose in male Sprague-Dawley rats, $\mathrm{C}_{\max }$ was $0.73 \pm 0.14 \mu \mathrm{g} / \mathrm{ml}$ and AUC $1.81 \pm 0.24 \mu \mathrm{g} . \mathrm{h} / \mathrm{ml}$ $\left(10.86 .10^{4} \pm 1.44 \cdot 10^{4}\right.$ ng. $\left.\mathrm{min} / \mathrm{ml}\right)$ [40]. Although a promising high AUC was obtained after oral administration of Ptx-loaded SLN, the effect of SLN in oral absorption should be evaluated by comparison with Ptx solution: the AUC of Ptx after oral administration was 2.5-fold improved by the encapsulation in SLN. When the mean relative AUC obtained with the oral Ptx commercial formulation was compared with the mean AUC obtained after intravenous administration, the absolute oral bioavailability was found to be very low at $1.2 \%$. This poor oral exposure of Ptx from the Ptx commercial formulation in rats was lower than values reported in the previous study (6.5\%) but different doses and rat species were used [5]. The low oral bioavailability of Ptx is usually explained by its low aqueous solubility, its high affinity for intestinal P-gp and its high affinity for the CYP isoenzymes. P-gp is expressed in enterocytes and can actively transport Ptx out to the gut lumen. The CYP isoenzymes, which are present in intestinal wall and in liver, metabolize Ptx (presystemic first-pass effect). A high interindividual variability in Ptx oral absorption has yet been observed for Ptx commercial formulation, this could be explained in part by the interindividual variability in P-gP and CYP expression. Unfortunately, standard LNCs and LNCs with chitosan presented no beneficial effect in reducing interindividual variability (variation of $69 \%$ in AUC for both LNCs vs. $49 \%$ for Ptx commercial formulation). After oral administration of a Taxol generic or a Ptx formulation with less Cremophor EL, associated with cyclosporin A, a high interindividual variability was observed in human (coefficient of variation in AUC varied from 14.5 to $63.9 \%$ according to the dose) [41]. On the opposite, $\mathrm{PEG}_{2000}$-amino postinserted LNCs present an effect on the reduction in interindividual variability (variation of $36 \%$ in AUC). It has been showed in a previous study that this formulation diffuses more easily into mucus than Ptx commercial formulation [12] and has less interaction with mucus than standard LNCs [42]. The high variability of Ptx commercial formulation and standard LNCs was thus also probably caused by mucus barrier.

When Ptx was loaded in standard LNCs and administered orally, the maximal plasma concentration was increased from $190 \pm 93$ (Ptx alone) to $612 \pm 323 \mathrm{ng} / \mathrm{ml}$ and the AUC was significantly raised from $3.2 \cdot 10^{4} \pm 1.6 \cdot 10^{4}$ to $9.8 \cdot 10^{4} \pm 6.7 \cdot 10^{4} \mathrm{ng} \cdot \mathrm{h} / \mathrm{ml}$ $(\mathrm{p}<0.05)$. This threefold improvement was in agreement with values reported by Peltier $e t$ al. [5]. Sparreboom et al. have demonstrated that P-gp in the intestinal mucosa limits the orally bioavailability of Ptx by effluxing Ptx in the lumen [15]. After the administration of $10 \mathrm{mg} \mathrm{Ptx} / \mathrm{kg}$ body weight, plasma systemic exposure was about sixfold higher in mice lacking functional P-gp (Mdrla ${ }^{-/}$knockout), than in wildtype mice [15]. Similarly, P-gp reduces bioavailability of Ptx after oral administration in human. Apparent bioavailability of oral Ptx was poor (only 4\%) in human and was eightfold improved by the co-administration with cyclosporin A, a P-gp inhibitor [43]. LNCs have the ability to inhibit the enterocyte P-gp, a drug pump efflux [16], due to the presence of Solutol ${ }^{\circledR} \mathrm{HS} 15$ on the external layer of nanocapsules. The improvement of

Table 2. Pharmacokinetic parameters after intravenous or oral administration of paclitaxel commercial formulation and paclitaxel-loaded lipid nanocapsules.

\begin{tabular}{|c|c|c|c|c|}
\hline Formulation & $C_{\max } \mathrm{ng} / \mathrm{ml}$ & $\mathrm{AUC}_{\text {last }} \mathrm{ng} / \mathrm{ml} * \min$ & $\mathrm{MRT}_{\text {last }} \min$ & $\begin{array}{l}\text { Relative oral } \\
\text { bioavailability (\%) }\end{array}$ \\
\hline Ptx commercial formulation iv. $(n=4)$ & $16,759 \pm 2336^{\dagger}$ & $5.2 \mathrm{E}+05 \pm 1.3 \mathrm{E}+05^{\dagger}$ & $77 \pm 27$ & - \\
\hline Standard LNCs iv. $(n=6)$ & $9905 \pm 1517$ & $2.5 \mathrm{E}+05 \pm 2.9 \mathrm{E}+04$ & $54 \pm 14$ & - \\
\hline LNCs postinserted with PEG $_{2000}$-amino iv. $(n=6)$ & $16,840 \pm 3224^{\dagger}$ & $4.7 \mathrm{E}+05 \pm 1.2 \mathrm{E}+05^{\dagger}$ & $80 \pm 42$ & - \\
\hline Ptx commercial formulation p.o. $(n=7)$ & $190 \pm 93^{\S}$ & $3.2 E+04 \pm 1.6 E+04^{\S}$ & $179 \pm 19$ & 1.2 \\
\hline Standard LNCs p.o. $(n=6)$ & $612 \pm 323^{\ddagger}$ & $9.8 \mathrm{E}+04 \pm 6.7 \mathrm{E}+04^{\ddagger}$ & $195 \pm 86$ & 3.8 \\
\hline LNCs postinserted with PEG $_{2000}$-amino p.o. $(n=7)$ & $2054 \pm 880^{\neq \S}$ & $3.6 \mathrm{E}+05 \pm 1.3 \mathrm{E}+05^{\ddagger \S}$ & $168 \pm 19$ & 14.0 \\
\hline LNCs with chitosan p.o. $(n=7)$ & $802 \pm 503^{\ddagger}$ & $1.3 \mathrm{E}+05 \pm 8.7 \mathrm{E}+04^{\ddagger}$ & $173 \pm 52$ & 4.9 \\
\hline
\end{tabular}




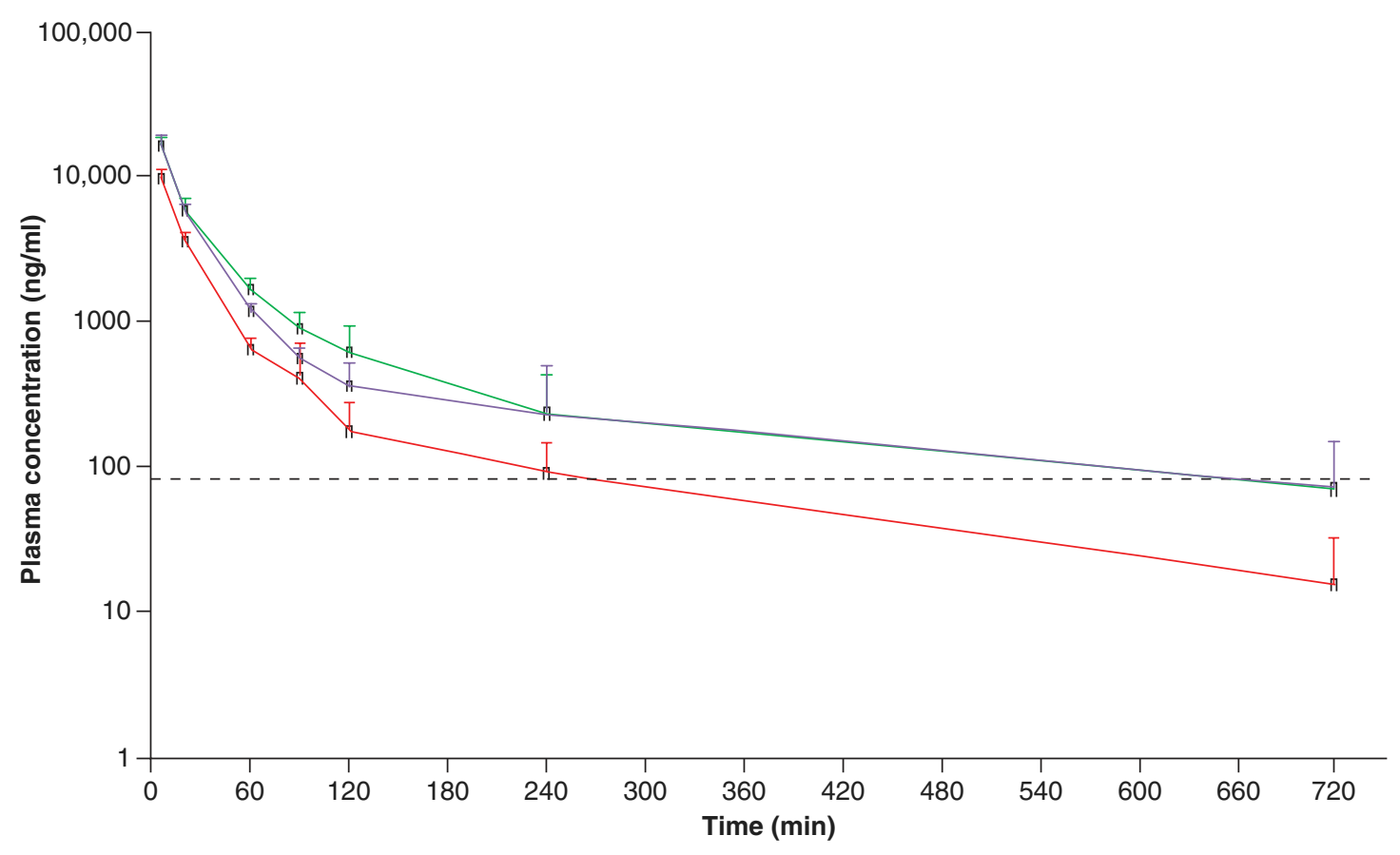

Figure 3. Plasma paclitaxel concentration-time profiles after the intravenous administration of a $5 \mathrm{mg} / \mathrm{kg}$ dose of paclitaxel. Red: standard LNCS $(n=6)$; violet: LNCs postinserted with $\mathrm{PEG}_{2000}$-amino $(n=6)$; green: Ptx commercial formulation $(n=4)$. Each point represents mean \pm standard deviation.

oral Ptx bioavailability with its encapsulation in LNC may be due to this property. Therefore, when Ptx is encapsulated in LNCs, its intestinal first pass effect may be reduced by decreasing its interaction with both P-gp and CYP.

After oral administration of LNCs with chitosan, a PK profile similar to the one obtained with standard LNCs was observed. Chitosan is known to improve oral bioavailability of drugs such as peptides [44] or hydrophobic drugs [45]. Chitosan micelles enhanced Ptx accumulation in Caco-2 cells [21] and the cellular association and cytotoxicity of Ptx were significantly improved by chitosan-PLGA particles [46]. That is why it was used to improve oral absorption of Ptx. The oral bioavailability of Ptx was improved threefold after encapsulation in chitosan micelles compared with Taxol generic [47]. However, chitosan-LNCs did not improve oral bioavailability of Ptx as compared with standard LNCs. The chitosan coating was not effective, probably because it was not stable in gastrointestinal medium or the benefit was insufficient to observe significant improvement as compared with standard LNCs.

When Ptx was loaded in $\mathrm{PEG}_{2000}$-amino postinserted LNCs, the maximum plasma concentration was increased from $612 \pm 323$ (standard LNCs) to $2054 \pm 880 \mathrm{ng} / \mathrm{ml}$ and the AUC was significantly raised from $9.8 \cdot 10^{4} \pm 6 \cdot 7 \cdot 10^{4}$ to $3 \cdot 6 \cdot 10^{5} \pm 1.3 \cdot 10^{5} \mathrm{ng} \cdot \mathrm{h} / \mathrm{ml}$ $(p<0.05) . P E G_{2000}$-amino postinserted LNCs were designed to minimize its retention in mucus. This optimization increased by 3.7- and 11.7-fold Ptx bioavailability compared with standard LNCs and Ptx commercial formulation, respectively. It was demonstrated that the coating of particles with PEG increased diffusion through the mucus layer [48] if PEG had an optimal molecular weight [49] and if coating was dense enough [50]. These muco-penetrating particles used to promote oral absorption of drug, improve efficiently the bioavailability of Ptx [51].

DSPE-PEG $_{2000}$ grafted with amino function led to neutral charge at the LNC surface and our previous study demonstrated that the diffusion of Ptx in mucus was improved after encapsulation in neutral or positively charged LNCs [42].

In anticancer formulation development, the choice of the animal model should be made carefully. In our case, the activity of the different formulations of Ptx was evaluated on a syngeneic model: a subcutaneous isograft of 9L tumor cell performed in Fisher rats. This model has been used before in the same conditions by other teams [52,53]. The use of a syngeneic model was justified by the fact that with this kind of model the immune system of the animal remains active which is very important to evaluate nanomedicine that can be rapidly inactivated by the immune system [36]. The second reason to use an isograft and not a xenograft involv- 
ing human cancer cells was dictated by the fact that the absorption of Ptx formulation in nude animals was very low and almost undetectable in blood (personal data not shown), thus jeopardizing its activity against cancer cells. The choice of 9L cells was made because these cells are resistant to Ptx and, in our study, we wanted to see if the encapsulation in colloidal carriers could reverse this resistance after intravenous or oral administration, a result that was previously observed on F98 isografts with the LNCs [14]. A subcutaneous model was also preferred over an orthotopic model (which is normally closer to the real disease) because it was much simpler to implement and had shown its ability to discriminate between formulations [14]. In previous studies we have injected Ptx LNCs every week in rats [54] and we have demonstrated a good tolerance of this procedure. This is why this protocol was chosen here. In fact this protocol mimics clinical practice

\section{(A)}

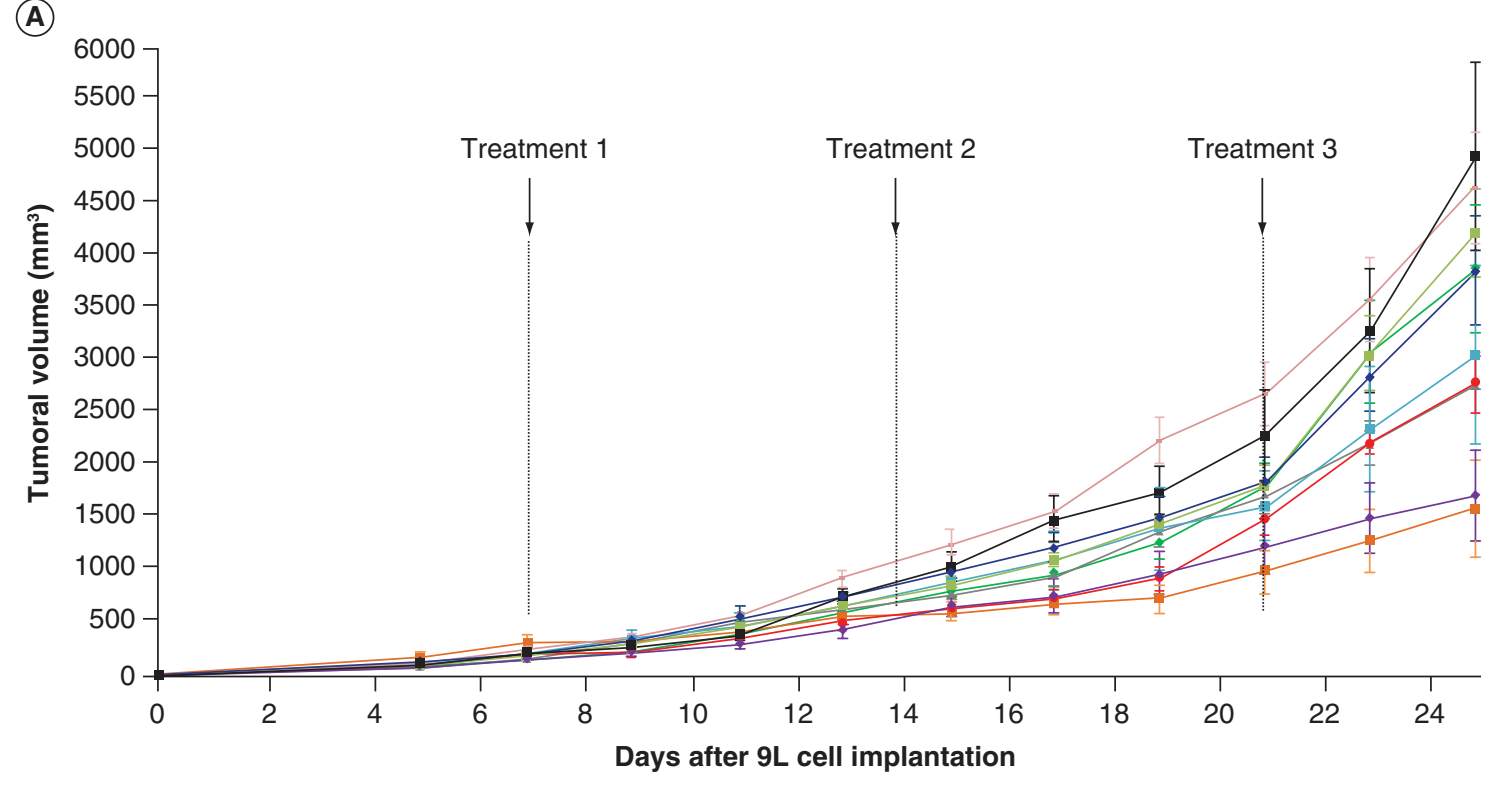

(B)

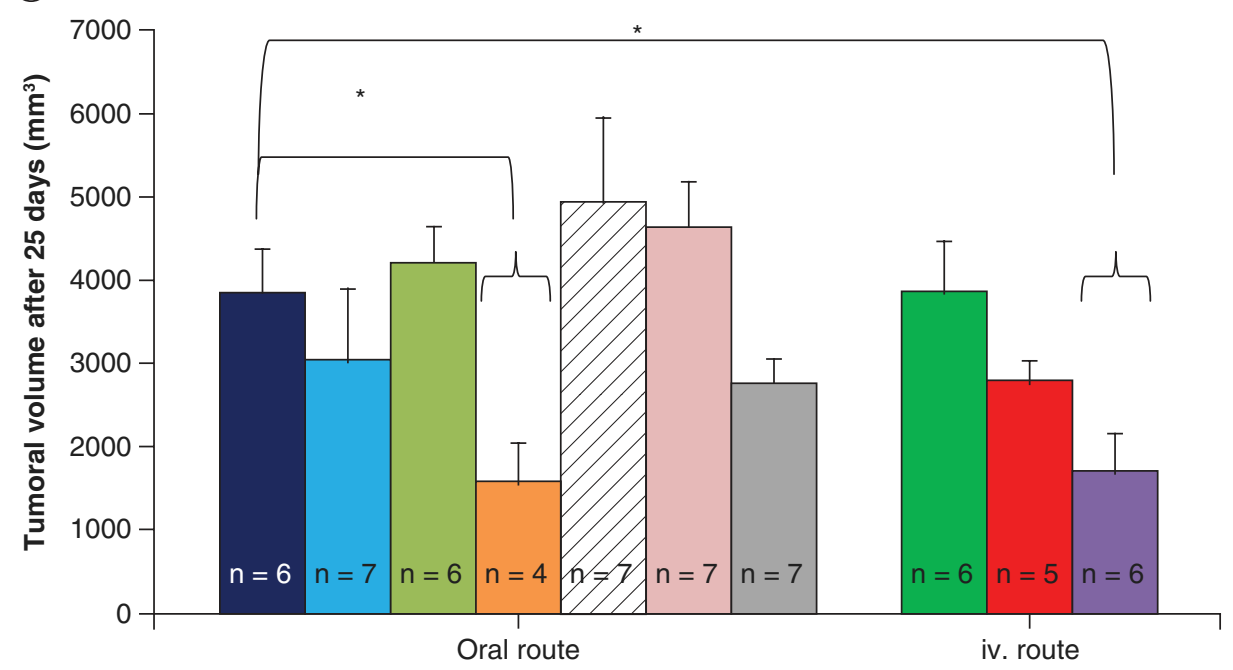

Figure 4. In vivo effects of paclitaxel-loaded lipid nanocapsules treatments on the growth of 9L glioma cells subcutaneous implanted on Fisher rats. (A) Tumoral volume-time profiles; (B) tumoral volume at day 25 postimplantation. Orange: standard LNCs per os (p.o.); pink: LNCs postinserted with PEG $_{2000}$-amino p.o.; gray: LNCs with chitosan p.o.; light green: Ptx commercial formulation p.o.; red: standard LNCs iv; purple: LNCs postinserted with $\mathrm{PEG}_{2000}$-amino iv; dark green: Ptx commercial formulation iv; navy: physiologic serum p.o.; light blue: blank LNCs p.o.; diagonal lined: blank LNCs postinserted with $\mathrm{PEG}_{2000}$-amino p.o. Each bar represents mean \pm SEM. LNCs: Lipid nanocapsules; Ptx: Paclitaxel. 
(175 mg/m² dose every 3 weeks) but with adaptation to a small rodent taking into account a faster elimination rate and metabolism.

On this animal model, our results showed that after intravenous injection, Ptx could be effective against these resistant tumors, only if encapsulated in LNCs. The Ptx commercial formulation, Taxol generic, remain inactive at the dose used on this model. This can be explained by the P-gp inhibition ability of the LNCs $[14,16]$ and also on the preferential diffusion into subcutaneous tumors of these nanocarriers [39]. LNCs with chitosan were not injected intravenously because they were not tolerated by the animals.

After oral route, the activities of the different types of LNCs are not completely identical. In fact PEG $_{2000}$-amino postinserted LNCs, which were the most active formulation after intravenous injection, were not found able to slow down the tumor-cell growth. At the same time, after PK studies we found that the AUC of these formulations was the most important. A hypothesis to explain this surprising result is that PEG ${ }_{2000}$-amino postinserted LNCs were able to enhance Ptx absorption but were destroyed during this process. Thus high amount of free Ptx are detected in the blood but the molecule can then be effluxed by the P-gp present in 9L cells preventing its cytotoxic activity. Ptx could not be determined in tumor to check this hypothesis because the study was performed during a too long time after treatment, in order to evaluate the tumor growth. Our study demonstrates that an increase in plasma AUC does not always predict a better pharmacological activity in the case of nanomedicines. In fact, standard LNCs displayed a lowest AUC after oral administration but kept their activity against Ptx-resistant tumors. These results confirm that besides the bioavailability issue, it is also very interesting to design nanocarriers being able to be absorbed while keeping their integrity [55].

\section{Conclusion}

This study is the first in which Ptx-LNCs were evaluated using PK and PD on same animal model. This $\mathrm{PK} / \mathrm{PD}$ coupling revealed unexpected results. In fact, the encapsulation of Ptx in LNCs has led to an improvement of oral Ptx exposure compared with Ptx commercial formulation and an activity over Ptx resistant cell line on a subcutaneous isograft in Fisher rats, after intravenous and oral administration. But, the formulation displaying the highest AUC after oral route $\left(\mathrm{PEG}_{2000}\right.$-amino postinserted LNCs) was not effective anymore after absorption. Standard LNCs was the only formulation that was effective orally. This study showed that the relation between AUC and pharmacological effect which is a corner stone of PK/PD studies has to be taken with caution in the case of nanomedicines. In fact, if the carrier is modified during its journey to the tumor or if the drug is released, the activity is not linked to the AUC in the case of resistant tumor, where the nanocarrier plays a significant role for activity.

\section{Future perspective}

This study showed a discrepancy between PK and PD data on some nanomedicine formulations. It is now important to determine the mechanism of this surprising result. To do so, we will assess the stability of the nanocapsules in vivo during the absorption process by fluorescence resonance energy transfer studies (as was previously done in vitro using mucus [12]). Ptx concentration measurement in the tumor can also contribute to understand why some formulations remain active against this Ptx resistant tumors and why other failed to be effective.

The activity of our formulations on orthotopic model without an overexpression of P-gp should also be determined and compared with the result presented in this paper. Because our Ptx formulations have previously demonstrated a very good tolerance [10], it is also possible to envision a treatment group with higher Ptx doses than what is possible with the commercial Ptx formulation (dose-limited toxicity) in order to characterize dose effect on these tumors. Finally, in long term, other drugs could be encapsulated in PEG $_{2000}$-amino postinserted LNCs to allow their oral administration.

\section{Acknowledgements}

The authors would like to thank X Declève (University of Paris Descartes) for his kind advice on the manuscript.

\section{Financial \& competing interests disclosure}

Anne-Claire Groo is a fellow from Ethypharm SA and received a research grant from Association Nationale de la Recherche et de la Technologie (ANRT). The authors have no other relevant affiliations or financial involvement with any organization or entity with a financial interest in or financial conflict with the subject matter or materials discussed in the manuscript apart from those disclosed.

\section{Ethical conduct}

The authors state that they have obtained appropriate institutional review board approval or have followed the principles outlined in the Declaration of Helsinki for all human or animal experimental investigations. In addition, for investigations involving human subjects, informed consent has been obtained from the participants involved. 
Executive summary

Pharmacokinetic study

- Encapsulation of paclitaxel (Ptx) in lipid nanocapsules (LNCs) improved its oral exposure.

- $\mathrm{PEG}_{2000}$-amino postinserted LNCs displayed the highest area under concentration-time curve after oral route.

Pharmacodynamic study on Ptx-resistant tumors

- The only formulation effective orally was standard LNCs.

- The best formulation after intravenous injection was PEG ${ }_{2000}$-amino postinserted LNCs.

Pharmacokinetic/pharmacodynamic

- No relation pharmacokinetic/pharmacodynamic after oral administration of nanovector was observed.

- $\mathrm{PEG}_{2000}$-amino postinserted LNCs improved bioavailability but no efficacy.

- Standard LNCs displayed limited bioavailability but efficacy.

Hypothesis

- Loss of the PEG 2000 -amino postinserted LNCs integrity after absorption lead to action of P glycoprotein and

prevented enhanced permeation and retention effect causing loss of efficacy against tumoral model.

Two interesting tools were obtained

- $\mathrm{PEG}_{2000}$-amino postinserted LNCs as candidate for tumors without P glycoprotein for oral administration.

- Standard LNCs as candidate against resistant tumors.

\section{References}

Papers of special note have been highlighted as:

- of interest; $\bullet \bullet$ of considerable interest.

1 Galletti E, Magnani M, Renzulli ML, Botta M. Paclitaxel and docetaxel resistance: molecular mechanisms and development of new generation taxanes. ChemMedChem 2(7), 920-942 (2007).

2 Yared JA, Tkaczuk KH. Update on taxane development: new analogs and new formulations. Drug Des. Devel. Ther. 6, 371-384 (2012).

3 Gelderblom H, Verweij J, Nooter K, Sparreboom A. Cremophor EL: the drawbacks and advantages of vehicle selection for drug formulation. Eur. J. Cancer 37(13), 1590-1598 (2001).

4 Hureaux J, Lagarce F, Gagnadoux F, Clavreul A, Benoit JP, Urban T. The adaptation of lipid nanocapsule formulations for blood administration in animals. Int. J. Pharm 379(2), 266-269 (2009).

5 Peltier S, Oger JM, Lagarce F, Couet W, Benoit JP. Enhanced oral paclitaxel bioavailability after administration of paclitaxel-loaded lipid nanocapsules. Pharm. Res. 23(6), 1243-1250 (2006).

6 Saliou B, Thomas O, Lautram N et al. Development and in vitro evaluation of a novel lipid nanocapsule formulation of etoposide. Eur. J. Pharm. Sci. 50(2), 172-180 (2013).

7 Vrignaud S, Hureaux J, Wack S, Benoit J-P, Saulnier P. Design, optimization and in vitro evaluation of reverse micelle-loaded lipid nanocarriers containing erlotinib hydrochloride. Int. J. Pharm. 436(1-2), 194-200 (2012).

8 Morille M, Passirani C, Dufort S et al. Tumor transfection after systemic injection of DNA lipid nanocapsules. Biomaterials 32(9), 2327-2333 (2011).

9 Resnier P, David S, Lautram N et al. EGFR siRNA lipid nanocapsules efficiently transfect glioma cells in vitro. Int. J. Pharm. 454(2), 748-755 (2013).

10 Hureaux J, Lagarce F, Gagnadoux F et al. Toxicological study and efficacy of blank and paclitaxel-loaded lipid nanocapsules after i.v. administration in mice. Pharm. Res. 27(3), 421-430 (2010).

11 Roger E, Lagarce F, Benoit JP. The gastrointestinal stability of lipid nanocapsules. Int. J. Pharm. 379 (2), 260-265 (2009)

12 Groo a-C, Saulnier P, Gimel J-C et al. Fate of Paclitaxel lipid nanocapsules in intestinal mucus in view of their oral delivery. Int. J. Nanomed. 8(1), 4291-4302 (2013).

13 Roger E, Lagarce F, Garcion E, Benoit JP. Lipid nanocarriers improve paclitaxel transport throughout human intestinal epithelial cells by using vesicle-mediated transcytosis. $J$. Control. Release 140(2), 174-181 (2009).

14 Garcion E, Lamprecht A, Heurtault B et al. A new generation of anticancer, drug-loaded, colloidal vectors reverses multidrug resistance in glioma and reduces tumor progression in rats. Mol. Cancer Ther. 5(7), 1710-1722 (2006).

15 Sparreboom A, Van Asperen J, Mayer U et al. Limited oral bioavailability and active epithelial excretion of paclitaxel (Taxol) caused by P-glycoprotein in the intestine. Proc. Natl Acad. Sci. USA 94(5), 2031-2035 (1997).

-• Key paper showing that $\mathrm{P}$ glycoprotein (P-gp) in the intestinal mucosa limits the orally bioavailability of Ptx.

16 Roger E, Lagarce F, Garcion E, Benoit JP. Reciprocal competition between lipid nanocapsules and P-gp for paclitaxel transport across Caco-2 cells. Eur. J. Pharm. Sci. 40(5), 422-429 (2010).

- Inhibition of the enterocyte P-gp by LNCs.

17 Heurtault B, Saulnier P, Pech B, Proust JE, Benoit JP. A novel phase inversion-based process for the preparation of lipid nanocarriers. Pharm Res. 19(6), 875-880 (2002).

18 Bhardwaj V, Ankola DD, Gupta SC, Schneider M, Lehr CM, Kumar MNVR. PLGA nanoparticles stabilized with cationic surfactant: safety studies and application in oral delivery of paclitaxel to treat chemical-induced breast cancer in rat. Pharm. Res. 26(11), 2495-2503 (2009).

19 Agueros M, Zabaleta V, Espuelas S, Campanero MA, Irache JM. Increased oral bioavailability of paclitaxel by its 
encapsulation through complex formation with cyclodextrins in poly(anhydride) nanoparticles. J. Control. Release 145(1), 2-8 (2010).

$20 \mathrm{Jin} \mathrm{J}, \mathrm{Bi} \mathrm{H}, \mathrm{Hu} \mathrm{J}$ et al. Enhancement of oral bioavailability of paclitaxel after oral administration of Schisandrol B in rats. Biopharm. Drug Dispos. 31(4), 264-268 (2010).

21 Mo R, Jin X, Li N et al. The mechanism of enhancement on oral absorption of paclitaxel by $\mathrm{N}$-octyl-O-sulfate chitosan micelles. Biomaterials 32(20), 4609-4620 (2011).

22 Iqbal J, Sarti F, Perera G, Bernkop-Schnürch A. Development and in vivo evaluation of an oral drug delivery system for paclitaxel. Biomaterials 32(1), 170-175 (2011).

23 Yang S, Gursoy RN, Lambert G, Benita S. Enhanced oral absorption of paclitaxel in a novel self-microemulsifying drug delivery system with or without concomitant use of P-glycoprotein inhibitors. Pharm. Res. 21(2), 261-270 (2004).

24 Lian H, Zhang T, Sun J et al. Enhanced oral delivery of paclitaxel using acetylcysteine functionalized chitosanvitamin $\mathrm{E}$ succinate nanomicelles based on a mucus bioadhesion and penetration mechanism. Mol. Pharm. 10(9), 3447-3458 (2013).

25 Montaseri H, Mohammadi-Samani S, Zarea B, Sobhani Z, Ahmadi F. Enhanced oral bioavailability of paclitaxel by concomitant use of absorption enhancers and P-glycoprotein inhibitors in rats. J. Chemother. 25(6), 355-361 (2013).

26 Choi JS, Li X. The effect of verapamil on the pharmacokinetics of paclitaxel in rats. Eur. J. Pharm. Sci. 24(1), 95-100 (2005).

27 Joshi N, Saha R, Shanmugam T, Balakrishnan B, More P, Banerjee R. Carboxymethyl-chitosan-tethered lipid vesicles: hybrid nanoblanket for oral delivery of paclitaxel. Biomacromolecules 14(7), 2272-2282 (2013).

28 Jain S, Kumar D, Swarnakar NK, Thanki K. Polyelectrolyte stabilized multilayered liposomes for oral delivery of paclitaxel. Biomaterials 33(28), 6758-6768 (2012).

29 Zabaleta V, Ponchel G, Salman H, Agueros M, Vauthier C, Irache JM. Oral administration of paclitaxel with pegylated poly(anhydride) nanoparticles: permeability and pharmacokinetic study. Eur. J. Pharm. Biopharm. 81(3), 514-523 (2012).

30 Lee CK, Choi JS. Effects of silibinin, inhibitor of CYP3A4 and P-glycoprotein in vitro, on the pharmacokinetics of paclitaxel after oral and intravenous administration in rats. Pharmacology 85(6), 350-356 (2010).

31 Park JH, Hur HJ, Woo JS, Lee HJ. Effects of silymarin and formulation on the oral bioavailability of paclitaxel in rats. Eur. J. Pharm. Sci. 45(3), 296-301 (2012).

32 Reagan-Shaw $S$, Nihal M, Ahmad N. Dose translation from animal to human studies revisited. FASEB J. 22(3), 659-661 (2008).

33 Bardelmeijer HA, Ouwehand M, Malingre MM, Schellens J, Beijnen JH, Van Tellingen O. Entrapment by Cremophor EL decreases the absorption of paclitaxel from the gut. Cancer Chemother. Pharmacol. 49(2), 119-125 (2002).

34 Gelderblom H, Verweij J, Van Zomeren DM et al. Influence of Cremophor El on the bioavailability of intraperitoneal paclitaxel. Clin. Cancer Res. 8(4), 1237-1241 (2002).
35 Van Tellingen O, Huizing MT, Panday VR, Schellens JH, Nooijen WJ, Beijnen JH. Cremophor EL causes (pseudo-) non-linear pharmacokinetics of paclitaxel in patients. $B r . J$. Cancer 81(2), 330-335 (1999).

- Crucial evidences showing that Cremophor EL causes nonlinear pharmacokinetics of Ptx.

36 Vonarbourg A, Passirani C, Saulnier P, Simard P, Leroux JC, Benoit JP. Evaluation of pegylated lipid nanocapsules versus complement system activation and macrophage uptake. J. Biomed. Mater. Res. A 78(3), 620-628 (2006).

37 Khalid MN, Simard P, Hoarau D, Dragomir A, Leroux JC. Long circulating poly(ethylene glycol)-decorated lipid nanocapsules deliver docetaxel to solid tumors. Pharm. Res. 23(4), 752-758 (2006).

38 Hoarau D, Delmas P, David S, Roux E, Leroux JC. Novel long-circulating lipid nanocapsules. Pharm. Res. 21(10), 1783-1789 (2004).

39 Morille M, Montier T, Legras P et al. Long-circulating DNA lipid nanocapsules as new vector for passive tumor targeting. Biomaterials 31(2), 321-329 (2010).

40 Baek JS, So JW, Shin SC, Cho CW. Solid lipid nanoparticles of paclitaxel strengthened by hydroxypropyl-betacyclodextrin as an oral delivery system. Int. J. Mol. Med. 30(4), 953-959 (2012).

41 Chu Z, Chen J-S, Liau C-T et al. Oral bioavailability of a novel paclitaxel formulation (Genetaxyl) administered with cyclosporin A in cancer patients. Anticancer Drugs 19(3), 275-281 (2008).

42 Groo a-C, Mircheva K, Bejaud J et al. Development of 2D and $3 \mathrm{D}$ mucus models and their interactions with mucus penetrating paclitaxel loaded lipid nanocapsules. Pharm. Res.31(7), 1753-1765 (2014).

43 Meerum Terwogt JM, Malingré MM, Beijnen JH et al. Coadministration of oral cyclosporin a enables oral therapy with paclitaxel. Clin. Cancer Res. 5(11), 3379-3384 (1999).

44 Prego C, Fabre M, Torres D, Alonso MJ. Efficacy and mechanism of action of chitosan nanocapsules for oral peptide delivery. Pharm. Res. 23(3), 549-556 (2006).

45 Siew A, Le H, Thiovolet M, Gellert P, Schatzlein A, Uchegbu I. Enhanced oral absorption of hydrophobic and hydrophilic drugs using quaternary ammonium palmitoyl glycol chitosan nanoparticles. Mol. Pharm. 9(1), 14-28 (2011).

46 Chakravarthi SS, Robinson DH. Enhanced cellular association of paclitaxel delivered in chitosan-PLGA particles. Int. J. Pharm. 409(1-2), 111-120 (2011).

47 Li H, Huo M, Zhou J et al. Enhanced oral absorption of paclitaxel in N-deoxycholic acid-N, O-hydroxyethyl chitosan micellar system. J. Pharm. Sci. 99(11), 4543-4553 (2010).

48 Lai Sk, Suk Js, Pace A et al. Drug carrier nanoparticles that penetrate human chronic rhinosinusitis mucus. Biomaterials 32(26), 6285-6290 (2011).

49 Wang YY, Lai SK, Suk JS, Pace A, Cone R, Hanes J. Addressing the PEG mucoadhesivity paradox to engineer nanoparticles that "slip" through the human mucus barrier. Angew. Chem. Int. Ed. 47(50), 9726-9729 (2008). 
50 Mert O, Lai SK, Ensign L et al. A poly(ethylene glycol)-based surfactant for formulation of drug-loaded mucus penetrating particles. J. Control. Release 157(3), 455-460 (2012).

51 Zabaleta V, Calleja P, Espuelas S et al. Mucopenetrating nanoparticles: vehicles for the oral administration of paclitaxel. Ann. Pharm. Fr. 71(2), 109-118 (2013).

- Improvement of the Ptx bioavailability by the particles coating with PEG.

52 Bansal A, Shuyan W, Hara T, Harris RA, Degrado TR. Biodisposition and metabolism of $\left[{ }^{18} \mathrm{~F}\right]$ fluorocholine in $9 \mathrm{~L}$ glioma cells and 9L glioma-bearing fisher rats. Eur. J. Nucl. Med. Mol. Imaging 35(6), 1192-1203 (2008).

53 Murphy S, Davey RA, Gu XQ et al. Enhancement of cisplatin efficacy by thalidomide in a 9L rat gliosarcoma model. J. Neurooncol. 85(2), 181-189 (2007).
54 Lacoeuille F, Hindre F, Moal F et al. In vivo evaluation of lipid nanocapsules as a promising colloidal carrier for paclitaxel. Int. J. Pharm. 344(1-2), 143-149 (2007).

55 Roger E, Lagarce F, Garcion E, Benoit JP. Biopharmaceutical parameters to consider in order to alter the fate of nanocarriers after oral delivery. Nanomedicine (London) 5(2), 287-306 (2010).

- Review paper showing the relation between nanoparticle features and intestinal barrier crossing.

56 National Research council of the national academies. Guide For The Care And Use of Laboratory Animals (8th Edition). The National academies press, Washington DC, USA (2011). 